\title{
Molecular dynamics study of the point defects in bec uranium
}

\author{
C. Ravi $\odot^{*}$ and R. Govindaraj \\ Materials Physics Division, Indira Gandhi Centre for Atomic Research, HBNI, Kalpakkam 603102, Tamilnadu, India \\ D. Alfe \\ Earth Sciences Department, University College London, London WC1E 6BS, United Kingdom
}

(Received 18 March 2020; revised 23 February 2021; accepted 27 April 2021; published 10 May 2021)

\begin{abstract}
Thermodynamic properties of bcc uranium with point defects are studied using $a b$ initio molecular dynamics (MD) simulations at $1100 \mathrm{~K}$. The simulations were performed with canonical ensembles of $\mathrm{U}_{127} \mathrm{M}_{1}, \mathrm{U}_{128} \mathrm{M}_{1}$, and $\mathrm{U}_{126} \mathrm{M}_{1} \square_{1}$ for $\mathrm{M}=\square$, He, Ne, Ar, Kr, Xe, Sr, Zr, I, Cs, and Pu disposed on a bec lattice lying within a $4 \times 4 \times 4$ cubic supercell. This work provides formation energies of substitutional, self, and solute interstitial atom defects as well as binding energies of $\mathrm{M}-\square$ pair defects. This work demonstrates that our computational scheme based on MD simulations gives reliable formation and binding energies of atomic defects in bcc uranium compared to conventional density functional theory calculations. The equilibrium volume, bulk modulus, and thermal expansion coefficient of pure bcc uranium obtained from our MD simulations compare very well with corresponding experimental results. The vacancy formation energy is predicted to be $0.88 \mathrm{eV}$. The experimental vacancy formation energy remains uncertain. Experimental study of the formation and binding energies of other point defects as well as the bulk modulus and thermal expansion coefficients of uranium with these defects is also not found in the literature. This work shows that point defects tend to decrease the bulk modulus and increase the thermal expansion coefficient of bcc uranium. The solute formation energies of noble gas atoms show a bearing on their size. A large solute (Xe) has a high formation energy, and vice versa. This size effect is not quite evident for the chemically reactive solutes, namely, $\mathrm{Sr}, \mathrm{Zr}, \mathrm{I}, \mathrm{Cs}$, and $\mathrm{Pu}$. Our MD simulations further show that vacancies are the favorable point defects in bcc uranium rather than both vacancies and self interstitials as predicted by earlier calculations. The formation energies of self interstitial atoms are found to be lower than those of solute interstitial atoms, each calculated in six different basic interstitial dumbbell configurations. That is, bcc $\mathrm{U}$ accommodates self interstitials more easily than decay or fission gas interstitials ( $\mathrm{He}, \mathrm{Kr}$, and $\mathrm{Xe}$ ). Further, $\mathrm{He}$ atoms are found to have comparable formation energies in the substitutional and interstitial locations. The fission product atoms $\mathrm{Kr}$ and $\mathrm{Xe}$ prefer to occupy vacant substitutional lattice sites rather than interstitial sites. Binding energies of divacancy and solute-vacancy pairs ( $0.31 \mathrm{vs}-0.69 \mathrm{eV}$ for the $\mathrm{Xe}-\square$ pair, for instance) from our MD simulation show that nucleation and growth of fission gas bubbles are supported by a thermodynamic driving force, whereas vacancies tend to stay apart. This is in agreement with literature reporting that bec uranium softens and swells mainly by agglomeration of noble gas bubbles.
\end{abstract}

DOI: 10.1103/PhysRevMaterials.5.053604

\section{INTRODUCTION}

$\mathrm{UO}_{2}$ is the most common fuel in nuclear power plants. $\mathrm{UO}_{2}$ has a high melting point and its performance under irradiation has been very good. Fundamental limitations of $\mathrm{UO}_{2}$ such as the low uranium density and poor thermal conductivity have nevertheless driven the development of advanced fuels such as UC, UN, and metallic alloys of uranium. Fast reactor fuel elements made of metallic alloys of cubic uranium, with enhanced dimensional stability over time, enable high burn-up and breeding besides the possibility of concurrent burning of radioactive minor actinides and fission products [1-8]. In a nuclear reactor, the fuels experience the most severe temperatures, irradiation damage, and chemical transmutation environment. The irradiation damage in fuels can

\footnotetext{
*ravic@igcar.gov.in
}

reach $1000 \mathrm{dpa}$, or about 10 times higher than the dose encountered by structural materials $[9,10]$. Accurate models of properties of fuel material and their evolution as a function of time in the reactor are therefore important for achieving predictive fuel performance simulations. A mechanistic fuel performance modeling framework based on microstructure evolution is considered to be promising. The main role of density functional theory (DFT) calculations in this fuel performance multiscale modeling framework has been to study the thermodynamic and kinetic properties of point defects in the fuel [5].

Atomic defects profoundly influence the properties of materials and impact their performance in applications. Atomic defects reduces the thermal conductivity of nuclear fuel. Atomic defects govern diffusion, which in turn influences recombination and agglomeration of vacancies and interstitials in nuclear fuel and hence formation of voids and interstitial loops which deteriorate mechanical performance. 
Further, in order to develop accurate models of fission gas diffusion, it is fundamental to understand their interaction with vacancies. It is thus important to be able to predict the equilibrium concentration of point defects and their evolution. The equilibrium concentration $c$ of point defects is governed by their formation energy $E^{f}$ and temperature $T$ [11,12] as $c \propto e^{-E^{f} / k_{B} T}$, where $k_{B}$ is the Boltzmann constant. Besides this, the binding energies of solutes to vacancies determine their diffusion kinetics [13-16]. Thus, the formation energies of point defects and their binding energies are important to characterize their influence on the properties of crystals.

Therefore calculation of the energetics of point defects has been a common field of DFT studies. DFT is often good enough to obtain sufficiently accurate results for the formation and binding energies of point defects [17-19]. But if one insists on calculation of $0 \mathrm{~K}$ properties of crystals that are unstable at this temperature, then meaningful results cannot be expected [5,20].

Body-centered cubic (bcc) uranium (known also as $\gamma$ uranium) is dynamically stabilized at high temperatures but unstable below $1050 \mathrm{~K}$ [21-24]. Because of this, there are not many DFT studies of properties of bcc uranium with atomic defects. Beeler et al. have nevertheless used DFT to calculate the energetics of point defects in bcc uranium $[25,26]$. They obtained an unrealistic relaxed structure in their calculation when all the structural degrees of freedom of the supercell model were allowed to relax. To avoid the undesirable relaxed structure, they used the selective dynamics scheme within DFT technique in which the point defect and the surrounding nearby shells of atoms were allowed to relax while the remaining atoms were frozen, referred to as the shell method (sm) [25]. Using the sm at $0 \mathrm{~K}$, they obtained the formation energies of atomic defects, namely, a vacancy and solute or impurity $\mathrm{Zr}, \mathrm{He}, \mathrm{Kr}$, or $\mathrm{Xe}$. But they stated that the sm is approximate, with inherent errors for energy minimization computation $[25,26]$.

Moreover, simulation of the high-temperature phase should account for the thermal effects. The molecular dynamics (MD) method is robust in that it includes thermal effects naturally and also allows calculations of the equation of state, thermal expansion coefficient, thermal conductivity, diffusion coefficient, etc. However, MD simulation of the properties of bec uranium is very scarce. Smirnov and Stegailov have used classical MD simulation to calculate the formation free energies of vacancies and interstitials in bcc uranium [27]. They showed that the self interstitials are the dominating defects, unlike in other metals where they are vacancies. But they concluded that $a b$ initio MD simulation is required to validate their results. On the other hand, ab initio MD simulation of point defects in uranium with a desirable system size of 1000 atoms, each with 14 valence electrons, would require extremely high computational power [27]. Nevertheless, Hood et al. have shown that $a b$ initio MD simulation of bcc uranium with a system of 128 atoms gives a reasonable equation of state [28]. Therefore, to improve our understanding of the basic properties of point defects in bcc uranium (a high-temperature phase), we use ab initio MD simulations to compute the formation and binding energies of an extended set of point defects, namely, a vacancy, and solute elements,

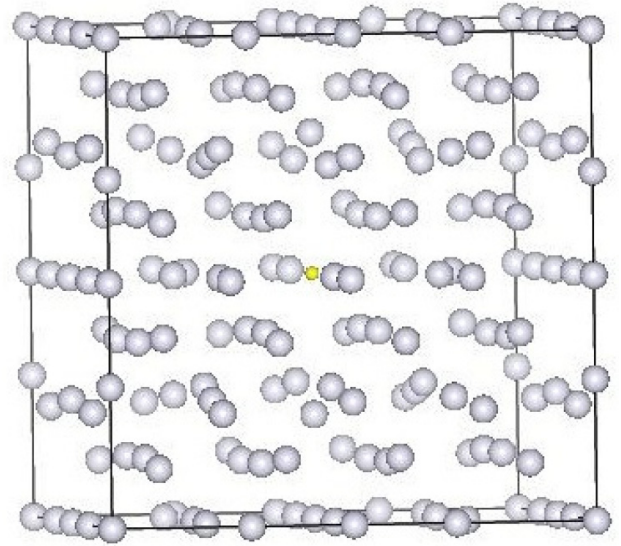

FIG. 1. Atomic relaxation in bcc U with a vacancy $\left(\mathrm{U}_{127} \square_{1}\right)$ obtained from $0 \mathrm{~K}$ DFT calculations (VASP-PAW-PBE, 500-eV cutoff, $5 \times 5 \times 5 k$ mesh) allowing complete relaxation of all structural degrees of freedom (size, shape, and ionic positions). The small sphere at the center of the supercell indicates the location of a vacancy. It is evident that the atoms are displaced appreciably from their ideal locations.

$\mathrm{He}, \mathrm{Ne}, \mathrm{Ar}, \mathrm{Kr}, \mathrm{Xe}, \mathrm{Sr}, \mathrm{Zr}$, I, Cs, and Pu. These elements were chosen because they are either fission or decay products or alloying additions in nuclear fuels. Although the amount of $\mathrm{Ne}$ and $\mathrm{Ar}$ created by uranium fission is negligible, it is useful to investigate the behavior of these species since they are often used to probe the structure of materials through ion implantation. In addition, they provide a link between the properties of small solutes such as $\mathrm{He}$ and large solutes like Xe [29,30].

The paper is organized as follows. After the introduction in this section, the computational scheme is outlined briefly in Sec. II. In the results section (Sec. III), we show that the equilibrium volumes of bcc uranium with point defects and their formation and binding energies obtained from our MD simulations are more reliable. Section IV presents a summary of the results.

\section{COMPUTATIONAL METHOD}

Bcc uranium is stabilized by temperature. Therefore, simulations above the stabilization temperature are more meaningful than DFT calculations at $0 \mathrm{~K}$. In order to see whether $0 \mathrm{~K}$ DFT works for bcc uranium, we calculated its equilibrium structure without and with a vacancy modeled using a bcc supercell with 128 lattice sites. The equilibrium volumes of $\mathrm{U}_{127} \square_{1}$ and $\mathrm{U}_{128}$ were obtained to be 2597.28 and $2574.78 \AA^{3}$, respectively. That is, $V_{0}\left(\mathrm{U}_{127} \square_{1}\right)>V_{0}\left(\mathrm{U}_{128}\right)$. Thus a vacancy causes expansion of bcc uranium lattice. It is evident from Fig. 1 that atoms are displaced appreciably from their ideal locations due to a vacancy. No atomic displacements have been observed in defect-free $\mathrm{U}_{128}$. The vacancy formation energy of $-4.12 \mathrm{eV}$ from these calculations indicates that bcc uranium is unstable, which is in agreement with its instability at low temperatures. This means that $0 \mathrm{~K}$ DFT calculations of point defect properties in high-temperature bcc uranium is not reliable. 
Nevertheless, if some artificial stability is imposed using the sm, we may obtain results that may have some meaning [25]. The focus of this work is, however, the reliable ab initio calculation of the formation and binding energies of point defects in bcc uranium. Therefore, we use ab initio molecular dynamics simulations, besides the shell method, to improve our understanding of the computational schemes and the basic thermodynamic properties of bcc uranium with point defects.

The formation energy of an atomic defect is a measure of the energy required to form the defect. The binding energy between a pair of atomic defects is a measure of the strength of the attractive or repulsive interaction between them. The expression for the formation energy $E^{f}$ of a substitutional defect $\mathrm{M}$, which is, in this work, either free atoms or pure elements, is given by $[12,18]$ :

$$
E^{f}=E\left(\mathrm{U}_{N-1} \mathrm{M}_{1}\right)-\frac{N-1}{N} E\left(U_{N}\right)-\frac{1}{n} E\left(M_{n}\right)
$$

where $E\left(\mathrm{U}_{N-1} \mathrm{M}_{1}\right)$ is the total energy of a bcc uranium supercell with $N$ lattice sites containing $(N-1) \mathrm{U}$ and a defect $\mathrm{M}$ atom. $E\left(\mathrm{U}_{N}\right)$ is the total energy of a bcc uranium supercell with $\mathrm{N}$ lattice sites. $E\left(\mathrm{M}_{n}\right)$ is the total energy of defect $\mathrm{M}$. Here, $n$ is 1 for the free atom solutes and it is the number of atoms in the unit cell for crystalline solutes. $E\left(\mathrm{M}_{n}\right)$ is 0 for $M$ a vacancy, denoted by $\square$. Point defects were introduced into the supercell model of bcc uranium by adding and/or removing select atoms. An isolated vacancy was created by removing a $U$ atom at a given lattice site. Substitutional atom defects were created by replacing a single $U$ atom with a solute $\mathrm{M}$ atom as in our previous work [18].

The interstitial sites are also potential locations for fuel and fission gas atoms because the fission fragments and neutrons move rapidly through the fuel, exchanging their energy to the lattice atoms until they come to rest, creating collision and displacement cascades, hence Frenkel pairs. In order to investigate fission gas diffusion and release, the probability of the fuel and fission gas atoms occupying different lattice locations must be known. Therefore, in addition to the substitutional locations, we have also calculated the formation energies of self and solute interstitials in bcc U considering the six different basic interstitial locations depicted in Fig. 1 of Han et al. [31]. The self interstitial atom (sia) formation energies are obtained from the following expression:

$$
E_{\text {sia }}^{f}=E\left(\mathrm{U}_{N+1}\right)-\frac{N+1}{N} E\left(\mathrm{U}_{N}\right),
$$

where $E\left(\mathrm{U}_{N+1}\right)$ and $E\left(\mathrm{U}_{N}\right)$ are the total energies of the systems with and without a self interstitial atom, respectively [31]. The formation energies of other interstitial atoms (oia) were calculated from the expression [32]

$$
E_{\text {oia }}^{f}=E\left(\mathrm{U}_{N} \mathrm{M}_{1}\right)-E\left(\mathrm{U}_{N}\right)-E\left(\mathrm{M}_{1}\right),
$$

where $E\left(\mathrm{U}_{N} \mathrm{M}_{1}\right)$ is the total energy of a supercell composed of $N \mathrm{U}$ atoms and one interstitial solute atom M. $E\left(\mathrm{M}_{1}\right)$ is the total energy of a solute atom M. Solute interstitial formation energies were calculated for the select elements $\mathrm{He}, \mathrm{Kr}$, and $\mathrm{Xe}$, as they are the important decay or fission gas elements produced in fission fuels in significant amounts. Self and solute interstitial atom configurations were created in accordance with Han et al. [31]. That is, the mixed dumbbell configurations were obtained by replacing one of the two atoms of the pure dumbbell with a solute atom $\mathrm{M}$.

The solute-vacancy (M- $\square$ ) binding energy $E^{b}$ is calculated from the expression [18]

$$
\begin{aligned}
E^{b}= & {\left[E\left(\mathrm{U}_{N-2} \mathrm{M}_{1} \square_{1}\right)+E\left(\mathrm{U}_{N}\right)\right] } \\
& -\left[E\left(\mathrm{U}_{N-1} \square_{1}\right)+E\left(\mathrm{U}_{N-1} \mathrm{M}_{1}\right)\right] .
\end{aligned}
$$

Substitutional solute-vacancy (M- $\square$ ) pairs were created by removing an $\mathrm{U}$ atom at a given site and replacing an $\mathrm{U}$ atom with a solute $\mathrm{M}$ atom at a nearest-neighbor site as in our earlier work [18]. The binding energies of self or solute interstitial atoms with vacancies are not considered here because these point defect clusters become more complex, requiring dedicated study.

The total energies required to calculate the formation and binding energies of point defects were computed with a $4 \times$ $4 \times 4$ bcc supercell having 128 lattice sites, namely, $\mathrm{U}_{128}$, $\mathrm{U}_{127} \mathrm{M}_{1}, \mathrm{U}_{126} \mathrm{M}_{1} \square_{1}$ with substitutional point defects $\mathrm{M}=\square$, $\mathrm{He}, \mathrm{Ne}, \mathrm{Ar}, \mathrm{Kr}, \mathrm{Xe}, \mathrm{Sr}, \mathrm{Zr}$, I, Cs, and Pu. The $4 \times 4 \times 4$ bcc supercell has been found to be sufficient to obtain converged point defect energies in bcc iron [18,33], hence we assume it to be sufficient for bcc uranium. The total energy calculations were performed using the Vienna Ab initio Simulation Package (VASP) [34,35]. For the electron-ion interaction, the projector augmented wave (PAW) potentials [36,37] were used for the elements considered in this work. For the exchange correlation energy functional, the generalized gradient approximation of Perdew, Burke, and Ernzerhof (PBE) was used [38]. Methfessel-Paxton order 1 smearing of the Fermi surface was used, with a smearing width of $0.2 \mathrm{eV}$ [39]. A cutoff energy of $500 \mathrm{eV}$ was used for the plane-wave expansion of the electron wave functions. A $5 \times 5 \times 5 k$-point mesh generated according to the Monkhorst-Pack scheme was used to sample the Brillouin zone in all the $0 \mathrm{~K}$ total energy calculations with the convergence criterion set to $10^{-7} \mathrm{eV}$. As mentioned earlier, the sm freezes all the atoms other than the atomic defects and their nearest and next-nearest shells of atoms, besides freezing the shape and size of the supercell [25]. In our work the shape and size of the supercell are allowed to relax.

The MD simulations were performed with ensembles of $\mathrm{U}_{128}, \mathrm{U}_{127} \mathrm{M}_{1}$, and $\mathrm{U}_{126} \mathrm{M}_{1} \square_{1}$ with substitutional point defects $\mathrm{M}=\square, \mathrm{He}, \mathrm{Ne}, \mathrm{Ar}, \mathrm{Kr}, \mathrm{Xe}, \mathrm{Sr}, \mathrm{Zr}, \mathrm{I}, \mathrm{Cs}$, and $\mathrm{Pu}$ and ensembles of $\mathrm{U}_{129}, \mathrm{U}_{128} \mathrm{He}_{1}, \mathrm{U}_{128} \mathrm{Kr}_{1}$, and $\mathrm{U}_{128} \mathrm{Xe}_{1}$, with self and solute interstitial atom defects, disposed on a bcc lattice lying within the $4 \times 4 \times 4$ cubic supercell. The simulations were performed in the canonical (NVT) ensemble with the temperature controlled using an Andersen thermostat [40]. The idea is to couple the system to a heat bath by using stochastic impulsive forces that act occasionally on randomly selected particles. After stochastic collision, the chosen particle forgets its old velocity and picks its new velocity from a Maxwell-Boltzmann distribution at the imposed temperature [41]. These simulations were performed with the default cutoff energy for the plane-wave basis set and with a single $\Gamma k$ point for sampling the Brillouin zone.

We note that a $4 \times 4 \times 4$ bcc supercell with 128 lattice sites was chosen for our MD simulations because the convergence calculations by Hood et al. [28] on uranium supercells with 
TABLE I. Structure of the solute elements. Crystallographic data of the elements were taken from the SpringerMaterials online database [48]. Lattice parameters $a, b, c, \alpha, \beta$, and $\gamma$ are given, respectively, in $\AA$ and degrees. The lattice constant $a$ alone is given for Sr and Cs. For $\mathrm{Zr}, a$ and $c$ are listed. For I, $a, b$, and $c$ are given.

\begin{tabular}{|c|c|c|c|}
\hline \multirow[t]{2}{*}{ Element } & \multirow[t]{2}{*}{ Structure } & \multicolumn{2}{|c|}{ Lattice parameter } \\
\hline & & Experimental & DFT \\
\hline $\mathrm{He}$ & Free atom & & \\
\hline $\mathrm{Ne}$ & Free atom & & \\
\hline $\mathrm{Ar}$ & Free atom & & \\
\hline $\mathrm{Kr}$ & Free atom & & \\
\hline $\mathrm{Xe}$ & Free atom & & \\
\hline $\mathrm{Sr}$ & $\mathrm{FCC}(225)$ & 6.03 & 6.05 \\
\hline $\mathrm{Zr}$ & HCP(194) & $3.23,5.15$ & $3.24,5.16$ \\
\hline I & Orthorhombic(64) & $7.26,4.80,9.78$ & $7.69,4.56,9.76$ \\
\hline Cs & $\mathrm{BCC}(229)$ & 6.05 & 6.16 \\
\hline $\mathrm{Pu}$ & Monoclinic(11) & $6.17,4.82,10.99,90,101.80,90$ & $6.17,4.82,10.99,90,101.80,90$ \\
\hline
\end{tabular}

32, 54, and 128 atoms have shown that the energies, pressures, and structural properties, such as the radial distribution function, were almost the same between 54- and 128-atom supercells. In these MD simulations, the irreducible Brillouin zones of 54- and 128-atom supercells were sampled with the single $\Gamma k$ point. Moreover, several $a b$ initio MD studies can be found in the literature where a 128-atom supercell with single $\Gamma k$-point sampling has been sufficient to obtain reliable results [42-45]. One of these studies [44] has also shown that relaxation of the ionic shells around the vacancy in bcc $\mathrm{Na}$ is negligible after the fifth shell. This means that the longwavelength acoustic vibrations are likely to be insensitive to local variation of the lattice [46] due to point defects.

In VASP the electronic ground state is calculated exactly at each MD step using an efficient iterative matrix diagonalization and Pulay mixing schemes. We have also implemented an extrapolation of the electronic charge density from one step to the next, which is known to increase the efficiency of MD simulations by a factor of 2 [47]. Each simulation was performed for $16 \mathrm{ps}$ in steps of $2 \mathrm{fs}$ with the temperature $T$ fixed at $1100 \mathrm{~K}$. For each system, the MD simulations were performed at three different volumes. The total pressures and average energies of each of the systems at the three volumes $(V 1, V 2, V 3)$ were then fitted to obtain the equilibrium volumes and corresponding energies of every system at the given $T$ and $P=0$. These equilibrium energies and volumes are then used in the calculation of the point defect formation and binding energies as well as the bulk modulus and thermal expansion coefficients. Each of these MD simulations was performed with 120 processor cores on a high-performance parallel computing cluster, and each simulation was run for about $14000 \mathrm{~min}$.

Structural details of the reference phases used for solutes [18] considered in this work are listed in Table I. For the noble gas elements, the spin-polarized total energy of their free atoms have been used as reference-state energies. These free atom total energy calculations were performed by placing a single atom at the center of a $12-\AA$ cubic cell. For $\mathrm{Sr}, \mathrm{Zr}$, $\mathrm{I}, \mathrm{Cs}$, and $\mathrm{Pu}$, their respective elemental ground-state crystal structures have been used as reference states. Their total energies have been obtained through high-precision calculations. The total energy of the defect atoms, $E\left(\mathrm{M}_{n}\right)$, thus corresponds to $0 \mathrm{~K} . E\left(\mathrm{M}_{n}\right)$ should take its temperature dependence into account when Eq. (1) is used to compute the formation energies from the MD total energies at a finite temperature. We assume that the temperature dependence of $E\left(\mathrm{M}_{n}\right)$ is negligible in this work [12]. Our calculated lattice parameters of $\mathrm{Sr}, \mathrm{Zr}$, $\mathrm{I}$, and $\mathrm{Cs}$ are found to be in good agreement with their respective experimental values [48]. The total energy of $\mathrm{Pu}$ was calculated at its experimental lattice parameters because the PBE exchange correlation functional underestimates its unit cell volume by about $11 \%$. Considering spin-orbit coupling is reported to resolve this discrepancy [49] but it is an involved procedure and hence omitted.

\section{RESULTS AND DISCUSSION}

\section{A. Equilibrium volumes and energetics of atomic defects from the shell method}

The results from the sm calculation of the formation energies of point defects and vacancy-solute binding energies in bcc uranium together with the equilibrium volumes of their respective supercell models are listed in Table II. Formation energies given in parentheses are from Beeler et al. [25,26]. We see that our calculation reproduces these energies well. The discrepancy in the formation energies of $\mathrm{He}, \mathrm{Kr}$, and $\mathrm{Xe}$ is likely due to the enhanced cutoff energy and finer $k$-point mesh used in our work. Further, our calculations allow the volumes to relax, whereas Beeler et al. fix them at the equilibrium volume of pure uranium [25,26]. Our work gives additionally the formation energies of six more solute elements $(\mathrm{Ne}$, $\mathrm{Ar}, \mathrm{Sr}, \mathrm{I}, \mathrm{Cs}, \mathrm{Pu}$ ) and vacancy-solute binding energies of all nine elements considered in this work ( $\mathrm{He}, \mathrm{Ne}, \mathrm{Ar}, \mathrm{Kr}, \mathrm{Xe}$, $\mathrm{Sr}, \mathrm{I}, \mathrm{Cs}, \mathrm{Pu}$ ).

We see further in Table II that the sm gives a volume of $\mathrm{U}_{127} \square_{1}$, which is smaller by $0.4 \%$ compared to the volume of pure $\mathrm{U}_{128}$. (The decrease in density $N / V$ due to vacancy is because of the decrease in $N$, not because of the increase in $V$.) We have seen above, on the other hand, that the conventional DFT calculations give an increased volume for $U_{127} \square_{1}$ relative to a pure $\mathrm{U}_{128}$ supercell. Although this trend by the sm is acceptable, we see later that it is not maintained in other systems. 
TABLE II. Properties of bcc $\mathrm{U}_{128}, \mathrm{U}_{127} \square_{1}, \mathrm{U}_{127} \mathrm{M}_{1}$, and $\mathrm{U}_{126} \mathrm{M}_{1} \square_{1}$ (M = He, Ne, Ar, Kr, Xe, Sr, Zr, I, Cs, Pu) obtained from DFT calculations using the shell method. The volumes $(V)$ of the supercell models together with the formation energies $E^{f}$ and binding energies $E^{b}$ of atomic defects in bcc uranium are listed. Formation energies given in parentheses are from Beeler et al. $[25,26]$.

\begin{tabular}{|c|c|c|c|c|c|}
\hline System & $V\left(\AA^{3}\right)$ & $E^{f}(\mathrm{eV})$ & System & $V\left(\AA^{3}\right)$ & $E^{b}(\mathrm{eV})$ \\
\hline $\mathrm{U}_{128}$ & 2574.78 & & & & \\
\hline $\mathrm{U}_{127} \square_{1}$ & 2564.43 & 1.33 (1.384) & $\mathrm{U}_{126} \square_{1} \square_{1}$ & 2562.15 & -0.90 \\
\hline $\mathrm{U}_{127} \mathrm{He}_{1}$ & 2568.95 & 3.08 (1.803) & $\mathrm{U}_{126} \mathrm{He}_{1} \square_{1}$ & 2576.38 & -3.07 \\
\hline $\mathrm{U}_{127} \mathrm{Ne}_{1}$ & 2583.93 & 4.06 & $\mathrm{U}_{126} \mathrm{Ne}_{1} \square_{1}$ & 2581.97 & -3.24 \\
\hline $\mathrm{U}_{127} \mathrm{Ar}_{1}$ & 2616.48 & 5.10 & $\mathrm{U}_{126} \mathrm{Ar}_{1} \square_{1}$ & 2584.55 & -2.99 \\
\hline $\mathrm{U}_{127} \mathrm{Kr}_{1}$ & 2617.69 & $5.22(5.926)$ & $\mathrm{U}_{126} \mathrm{Kr}_{1} \square_{1}$ & 2598.09 & -2.41 \\
\hline $\mathrm{U}_{127} \mathrm{Xe}_{1}$ & 2618.17 & $5.20(5.549)$ & $\mathrm{U}_{126} \mathrm{Xe}_{1} \square_{1}$ & 2599.27 & -2.43 \\
\hline $\mathrm{U}_{127} \mathrm{Sr}_{1}$ & 2621.05 & 2.70 & $\mathrm{U}_{126} \mathrm{Sr}_{1} \square_{1}$ & 2603.58 & -2.64 \\
\hline $\mathrm{U}_{127} \mathrm{Zr}_{1}$ & 2578.25 & $0.40(0.394)$ & $\mathrm{U}_{126} \mathrm{Zr}_{1} \square_{1}$ & 2581.97 & -2.94 \\
\hline $\mathrm{U}_{127} \mathrm{I}_{1}$ & 2607.53 & 1.32 & $\mathrm{U}_{126} \mathrm{I}_{1} \square_{1}$ & 2584.47 & -3.62 \\
\hline $\mathrm{U}_{127} \mathrm{Cs}_{1}$ & 2622.26 & 4.47 & $\mathrm{U}_{126} \mathrm{Cs}_{1} \square_{1}$ & 2603.39 & -2.44 \\
\hline $\mathrm{U}_{127} \mathrm{Pu}_{1}$ & 2572.42 & 3.92 & $\mathrm{U}_{126} \mathrm{Pu}_{1} \square_{1}$ & 2581.59 & -2.91 \\
\hline
\end{tabular}

Comparison of the equilibrium volumes of $\mathrm{U}_{127} \mathrm{M}_{1}$ and $\mathrm{U}_{126} \mathrm{M}_{1} \square_{1}$ for solute $\mathrm{M}$ in Table II shows that they have a qualitative correspondence to the atomic radii of $\mathrm{M}$, which are $1.08,1.58,1.88,2.00,2.17,2.15,1.60,2.16,2.73$, and $1.64 \AA$, respectively, for $\mathrm{He}, \mathrm{Ne}, \mathrm{Ar}, \mathrm{Kr}, \mathrm{Xe}, \mathrm{Sr}, \mathrm{Zr}, \mathrm{I}, \mathrm{Cs}$, and $\mathrm{Pu}$. The atomic radius of $\mathrm{He}$ was taken from Zhang and $\mathrm{Xu}$ [50]. Atomic radii of other elements were taken from Kittel [51]. Atomic radii of $\mathrm{Sr}, \mathrm{Zr}, \mathrm{Cs}$, and $\mathrm{Pu}$ corresponds to their ions in 12-coordinated metals. Other atomic radii are of the inert gas configuration. We would like to note here that the atomic radius is fruitful in predicting interatomic spacing but it is not rigid [51]. Comparison of the equilibrium volumes of $\mathrm{U}_{127} \mathrm{M}_{1}$ with those of $\mathrm{U}_{126} \mathrm{M}_{1} \square_{1}$ shows that the volumes of $\mathrm{U}_{126} \mathrm{M}_{1} \square_{1}$ are reduced relative to those of $\mathrm{U}_{127} \mathrm{M}_{1}$ for $\mathrm{M}=$ $\mathrm{Ne}, \mathrm{Ar}, \mathrm{Kr}, \mathrm{Xe}, \mathrm{Sr}, \mathrm{I}$, and $\mathrm{Cs}$ but increased for $\mathrm{M}=\mathrm{He}, \mathrm{Zr}$, and $\mathrm{Pu}$. We relate this increase in volumes to the low-temperature mechanical instability of bcc $U$ that caused its expansion with the introduction of a vacancy discussed previously. Thus the sm is not quite reliable, hence further discussion of the results is omitted. Therefore, the sm calculations of self and solute interstitials are also omitted.

\section{B. Equilibrium volumes and energetics of atomic defects from ab initio molecular dynamics simulations}

The results from MD simulations are described here. The MD simulations have been used here to calculate the thermodynamic properties of bcc uranium with point defects. Therefore, we have to ensure that the supercell models of uranium systems remain in the desired state during the simulations. The position autocorrelations becoming 0 and mean square displacements (MSDs) becoming nearly constant suggest that the systems remain in the same solid-state structure during the simulation [52,53]. The position autocorrelation (PAC) for a chosen atom, $i$, in a bcc crystal is given by $p_{i}(t)=$ $\left\langle\left(\mathbf{r}_{i}\left(t+t_{0}\right)-\mathbf{R}_{i}^{0}\right)\left(\mathbf{r}_{i}\left(t_{0}\right)-\mathbf{R}_{i}^{0}\right)\right\rangle$, where $\mathbf{r}_{i}$ is the time-varying position of the atom and $\mathbf{R}_{i}^{0}$ is the position of that atom's lattice site in the perfect bcc structure. The angular brackets denote the thermal average, which in practice is evaluated as an average over time origins, $t_{0}$, and atoms $i$. For long times $t$, vibrational displacements become uncorrelated, so that $p_{i}(t)=\left\langle\left(\mathbf{r}_{i}\left(t+t_{0}\right)-\mathbf{R}_{i}^{0}\right)\right\rangle\left\langle\left(\mathbf{r}_{i}\left(t_{0}\right)-\mathbf{R}_{i}^{0}\right)\right\rangle \rightarrow\left\langle r_{i}-R_{i}^{0}\right\rangle^{2}$, and if all atoms vibrate about bcc lattice sites, $\left\langle\mathbf{r}_{i}-\mathbf{R}_{i}^{0}\right\rangle=0$, so that $p_{i}(t) \rightarrow 0$ as $t \rightarrow \infty$. The mean square displacement is defined by $\Delta r^{2}(t)=\frac{1}{N} \sum_{i}\left[\mathbf{r}_{i}(t)-\mathbf{r}_{i}(0)\right]^{2}$. It is the mean squared distance over which the labeled atoms have moved in a time interval $t$. The MSD is used here mainly to distinguish between diffusive and nondiffusive behavior, as we are using a thermostat.

In order to establish our computational scheme based on canonical ensemble MD simulations, we first performed simulations for bcc $\mathrm{Zr}$ and $\mathrm{W}$, which are less complex metals than U. Figs. 2 and 3 show the average position autocorrelation PAC functions and MSDs in $\mathrm{Zr}_{128}, \mathrm{Zr}_{127} \square_{1}, \mathrm{~W}_{128}$, and
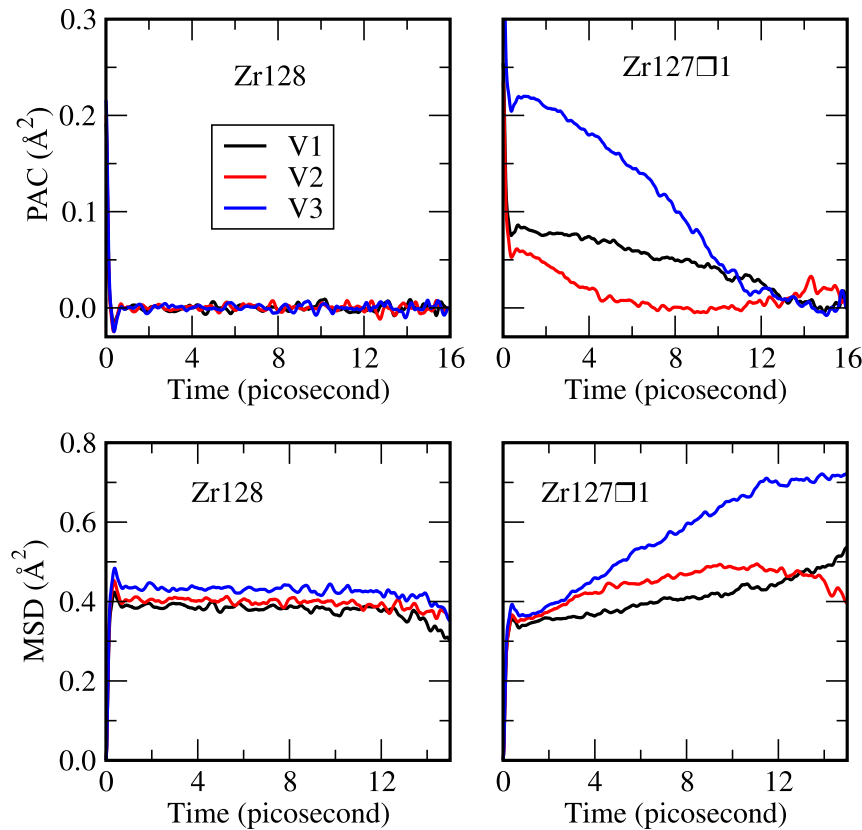

FIG. 2. Average position autocorrelation (PAC) functions and mean square displacements (MSDs) in bcc $\mathrm{Zr}_{128}$ and $\mathrm{Zr}_{127} \square_{1}$. MD simulations were performed at $1400 \mathrm{~K}$ at three different volumes, $V 1, V 2$, and $V 3$, such that $V 1<V 2<V 3$. 

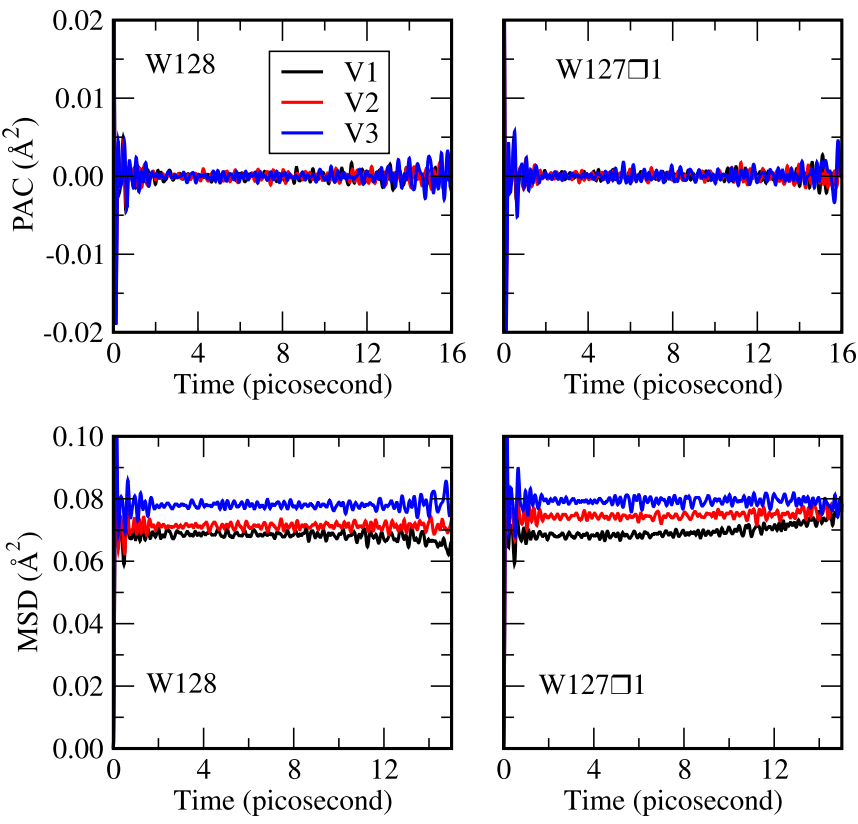

FIG. 3. Average position autocorrelation (PAC) functions and mean square displacements (MSDs) in bcc $\mathrm{W}_{128}$ and $\mathrm{W}_{127} \square_{1}$. MD simulations were performed at $1800 \mathrm{~K}$ at three different volumes, $V 1, V 2$, and $V 3$, such that $V 1<V 2<V 3$.

$\mathrm{W}_{127} \square_{1}$, respectively. It is evident that the PAC and MSD of pure $\mathrm{Zr}$ and $\mathrm{W}$ and of $\mathrm{W}$ with a vacancy become, respectively, 0 and constant, establishing that they remain in the same structure during the simulations (like textbook examples). The PAC and MSD of bcc Zr with a vacancy $\left(\mathrm{Zr}_{127} \square_{1}\right)$ become, respectively, 0 and constant at a lower rate than those of pure $\mathrm{Zr}$. This indicates that $\mathrm{Zr}_{127} \square_{1}$ also essentially retains its structure during the simulations.

The equilibrium energies of each of these systems at temperature $T$ were then obtained from their average energies at the three different volumes $(V 1, V 2, V 3)$ through fitting. In all our MD simulations, thermalization has been reached within about 650 fs. This initial 650 fs of the simulations was omitted when the average energies of the systems were calculated. That is, for every system, we have a set of three average energies, $E 1, E 2, E 3$, with respective volumes, $V 1$, $V 2, V 3$, and pressures, $P 1, P 2, P 3$. The equilibrium volume of the system, $V_{0}$, corresponding to $P=0$, is obtained by fitting the $V(P)$ data to a linear polynomial. The equilibrium energy of the system at $P=0$ is then calculated by fitting the $E(V)$ data to a quadratic polynomial with equilibrium volume $V_{0}$ from the $V(P)$ fitting. These energies were used in the calculations of the formation and binding energies of atomic defects [Eqs. (1)-(4)]. We have also obtained the bulk moduli, $B_{0}$, and volume thermal expansion coefficients, $\alpha$, respectively, from $B_{0}=-V \frac{d P}{d V}$ and $\alpha=\frac{1}{B_{0} T}\left[\frac{d E}{d V}+P\right]$ at $P=0$, which are part of the above $V(P)$ and $E(V)$ fitting schemes.

The results of our simulations for $\mathrm{Zr}$ and $\mathrm{W}$ are listed in Table III. The lattice parameter of pure bcc $\mathrm{Zr}$ (3.625 $\AA$ ) derived from our equilibrium volume at $1400 \mathrm{~K}$ is in very good agreement with the experimental value $(3.627 \AA)$ at $973 \mathrm{~K}$ [54]. Our bulk modulus of $83 \mathrm{GPa}$ appears to deviate from the experimental value of $66 \pm 3 \mathrm{GPa}$ [54] reported
TABLE III. Properties of bcc $\mathrm{Zr}_{128}, \mathrm{Zr}_{127} \square_{1}, \mathrm{~W}_{128}$, and $\mathrm{W}_{127} \square_{1}$ obtained from our $a b$ initio molecular dynamics simulation. The equilibrium volumes $(P=0)$ of the simulation supercells, $V_{0}$, together with the vacancy formation energies, $E^{f}$, are given. Estimates of the bulk moduli, $B_{0}$, and thermal volume expansion coefficients, $\alpha$, of these systems are also listed.

\begin{tabular}{lcccc}
\hline \hline System & $V_{0}\left(\AA^{3}\right)$ & $B_{0}(\mathrm{GPa})$ & $10^{-5} \alpha(1 / \mathrm{K})$ & $E^{f}(\mathrm{eV})$ \\
\hline $\mathrm{Zr}_{128}$ & 3048.46 & 83 & 3.02 & \\
$\mathrm{Zr}_{127} \square_{1}$ & 3031.58 & 82 & 3.31 & 1.05 \\
$\mathrm{~W}_{128}$ & 2115.97 & 294 & 1.42 & \\
$\mathrm{~W}_{127} \square_{1}$ & 2110.29 & 291 & 1.48 & 2.90 \\
\hline \hline
\end{tabular}

by Zhao et al. But they stated that more $P-V-T$ data are needed to better constrain their equation of state parameters. On the other hand, our bulk modulus is in good agreement with the $87 \mathrm{GPa}$ obtained from elastic constants at $1482 \mathrm{~K}$ reported by Heiming et al. [55]. They obtained the elastic constants from the force constants derived from Born-von Karman fits to the phonon dispersion curves from inelastic neutron scattering measurements. Our thermal expansion coefficient of $3.02 \times 10^{-5} / \mathrm{K}$ is also in good agreement with the experimental value of $2.91 \times 10^{-5} / \mathrm{K}$ [56]. The vacancy formation energy of $1.05 \mathrm{eV}$ determined from our simulation is smaller than the $1.75 \mathrm{eV}$ estimated from specific heat measurements [57]. But the latter value is considered to be higher than normal since it leads to a vacancy concentration which is a factor of 10 larger than those obtained with the aid of the differential dialatometry technique [57]. Furthermore, the vacancy formation energies show variation with temperature [12].

For pure $\mathrm{W}$, our lattice constant of $3.20 \AA$ derived from its equilibrium volume at $1800 \mathrm{~K}$ is in very good agreement with the literature value of $3.18 \AA[58]$. The bulk modulus of $294 \mathrm{GPa}$ also is in very good agreement with the literature [58] (305 GPa). For the vacancy formation energy, our simulation gives $2.90 \mathrm{eV}$, which is in reasonable agreement with the literature [32,58,59] (around $3.1 \mathrm{eV}$ ). The differences are likely because our results are for $1800 \mathrm{~K}$, whereas the literature results correspond to $0 \mathrm{~K}$. The thermal expansion coefficient of $\mathrm{W}$ predicted by our computational scheme is in good agreement with the literature [60-63]. These results thus lend credibility to our computational scheme.

\section{Substitutional and interstitial defects in bcc uranium}

We now turn to our results of the MD simulation of bcc U with point defects. Figs. 4 and 5 show the PACs and MSDs of $\mathrm{U}_{128}, \mathrm{U}_{127} \square_{1}$, and $\mathrm{U}_{127} \mathrm{M}_{1}(\mathrm{M}=\mathrm{He}, \mathrm{Ne}, \mathrm{Ar}, \mathrm{Kr}, \mathrm{Xe}, \mathrm{Sr}, \mathrm{Zr}, \mathrm{I}$, $\mathrm{Cs}, \mathrm{Pu})$. The PAC and MSD of systems with self and solute interstitials, namely, $\mathrm{U}_{129}, \mathrm{U}_{128} \mathrm{He}_{1}, \mathrm{U}_{128} \mathrm{Kr}_{1}$, and $\mathrm{U}_{128} \mathrm{Xe}_{1}$ are collected in the Supplemental Material (Figs. S1 to S8) [64]. These plots show that the PACs generally decrease to 0 with time. The MSDs tend to become constant with increasing time and are generally smaller than half the minimum bond lengths of these systems (1.52 Afor crowdion). This indicates that these systems remain in the same structure of uranium during the simulations. The thermodynamic properties of bcc uranium with point defects were then calculated in the same 

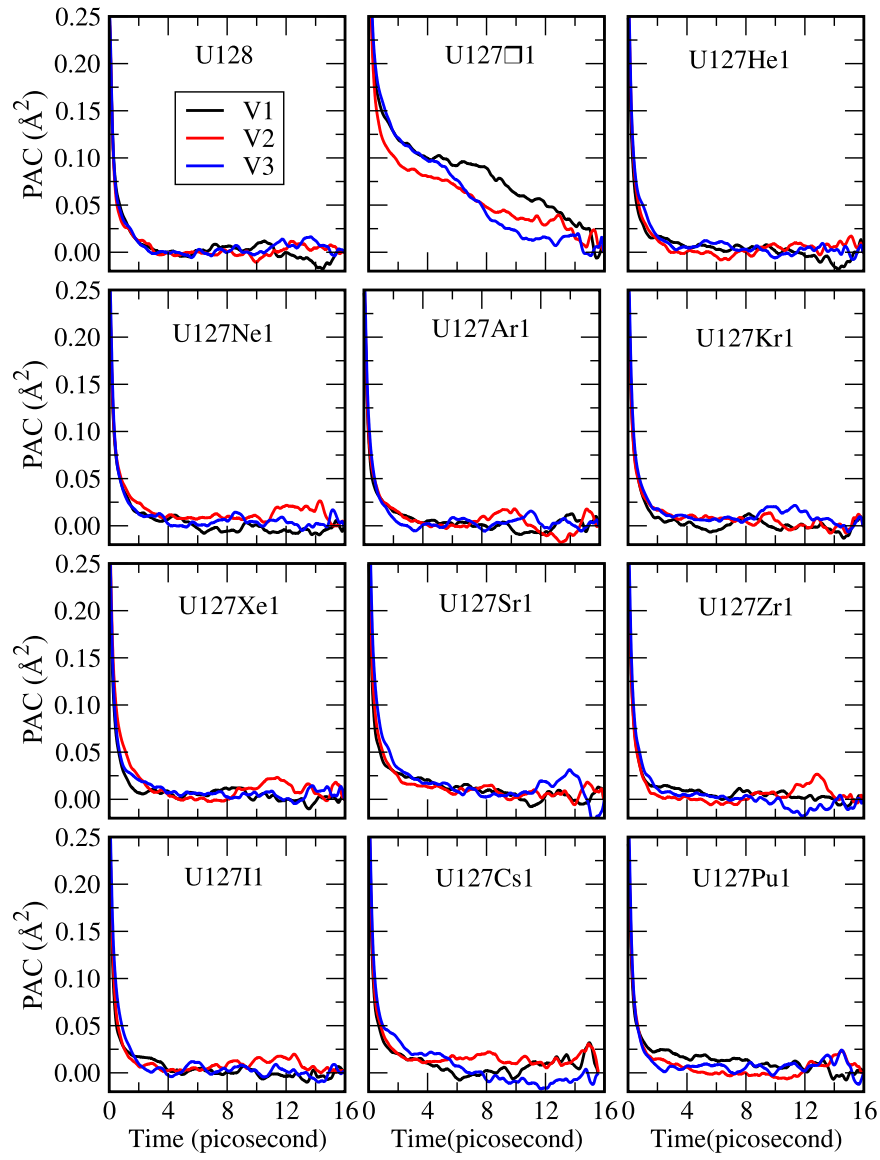

FIG. 4. Average position autocorrelation (PAC) functions in $\mathrm{U}_{127} \mathrm{M}_{1}$ with $\mathrm{M}=\square, \mathrm{He}, \mathrm{Ne}, \mathrm{Ar}, \mathrm{Kr}, \mathrm{Xe}, \mathrm{Sr}, \mathrm{Zr}, \mathrm{I}, \mathrm{Cs}, \mathrm{Pu}, \mathrm{U} . \mathrm{MD}$ simulations were performed at three different volumes, $V 1, V 2$, and $V 3$, such that $V 1<V 2<V 3$.

manner as described earlier for $\mathrm{Zr}$ and $\mathrm{W}$ and the results are listed in Tables IV and V.

The equilibrium lattice constant of bcc uranium, $3.50 \AA$, derived from the equilibrium volume of a pure bcc uranium supercell with 128 atoms, $2731.43 \AA^{3}$, in Table IV, obtained from our MD simulation at $1100 \mathrm{~K}$, is in very good agreement with the experimental lattice constant of $3.52 \AA$ at $1078 \mathrm{~K}$ $[7,65,66]$. We see further that the volume of $U_{127} \square_{1}$, that is, the volume of bcc uranium with a vacancy, is reduced compared to that of pure bcc uranium. This is remarkable because we have seen that the $0 \mathrm{~K}$ DFT calculation gives an equilibrium volume of $U_{127} \square_{1}$, which is higher than that of the pure $\mathrm{U}_{128}$ supercell by about $1 \%$. This is an important improvement because accurate calculation of the equilibrium volumes is basic for the reliability of the technique for the other properties calculated. The equilibrium volumes of other systems show a correspondence to the size of the solute or impurity atoms $\mathrm{M}$ as stated earlier.

Table IV further shows that our MD simulation predicts $0.88 \mathrm{eV}$ for the vacancy formation energy of bcc uranium. Matter et al. have investigated vacancy formation and phase transformations in uranium by positron annihilation. They have reported a lower limit of about $1 \mathrm{eV}$ for the monovacancy formation energy of bcc uranium through the trapping model [67]. Thus the vacancy formation energy of $0.88 \mathrm{eV}$
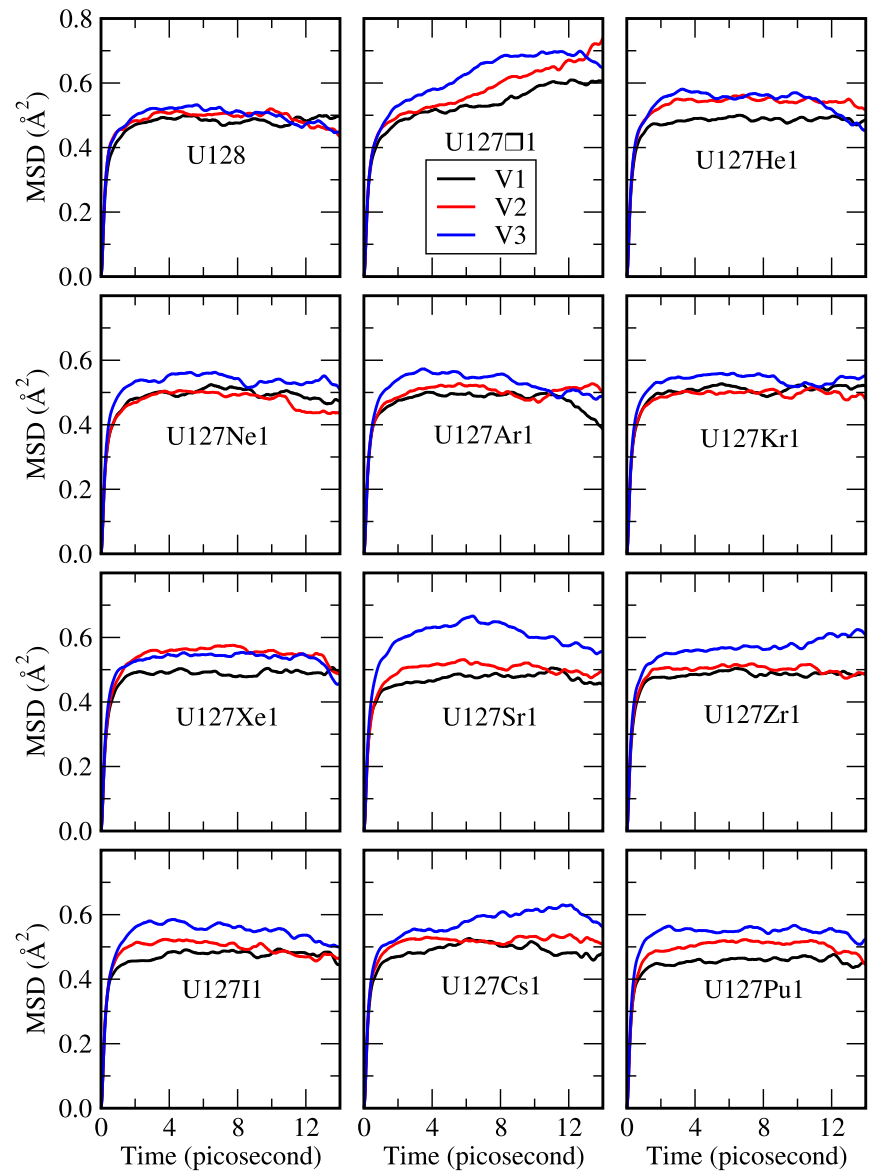

FIG. 5. Mean square displacements (MSDs) in $\mathrm{U}_{127} \mathrm{M}_{1}$ with $\mathrm{M}=\square, \mathrm{He}, \mathrm{Ne}, \mathrm{Ar}, \mathrm{Kr}, \mathrm{Xe}, \mathrm{Sr}, \mathrm{Zr}, \mathrm{I}, \mathrm{Cs}, \mathrm{Pu}, \mathrm{U}$. MD simulations were performed at three different volumes, $V 1, V 2$, and $V 3$, such that $V 1<V 2<V 3$

TABLE IV. Properties of $\mathrm{U}_{128}, \mathrm{U}_{127} \square_{1}$, and $\mathrm{U}_{127} \mathrm{M}_{1}(\mathrm{M}=\mathrm{He}$, $\mathrm{Ne}, \mathrm{Ar}, \mathrm{Kr}, \mathrm{Xe}, \mathrm{Sr}, \mathrm{Zr}$, I, Cs, $\mathrm{Pu}$ ) obtained from ab initio molecular dynamics simulation at $1100 \mathrm{~K}$. The equilibrium volumes $(P=0)$ of the simulation supercells, $V_{0}$, together with the formation energies, $E^{f}$, of atomic defects in bcc uranium are given. Estimates of the bulk moduli, $B_{0}$, and thermal volume expansion coefficients, $\alpha$, of these systems are also listed.

\begin{tabular}{lcccc}
\hline \hline System & $V_{0}\left(\AA^{3}\right)$ & $B_{0}(\mathrm{GPa})$ & $10^{-5} \alpha(1 / \mathrm{K})$ & $E^{f}(\mathrm{eV})$ \\
\hline $\mathrm{U}_{128}$ & 2731.43 & 109 & 2.21 & \\
$\mathrm{U}_{127} \square_{1}$ & 2715.71 & 102 & 3.24 & 0.88 \\
$\mathrm{U}_{127} \mathrm{He}_{1}$ & 2732.00 & 103 & 3.44 & 1.70 \\
$\mathrm{U}_{127} \mathrm{Ne}_{1}$ & 2735.75 & 101 & 3.57 & 2.54 \\
$\mathrm{U}_{127} \mathrm{Ar}_{1}$ & 2740.41 & 101 & 3.96 & 5.38 \\
$\mathrm{U}_{127} \mathrm{Kr}_{1}$ & 2747.28 & 101 & 3.15 & 5.58 \\
$\mathrm{U}_{127} \mathrm{Xe}_{1}$ & 2753.25 & 102 & 3.72 & 6.46 \\
$\mathrm{U}_{127} \mathrm{Sr}_{1}$ & 2753.08 & 97 & 4.77 & 2.10 \\
$\mathrm{U}_{127} \mathrm{Zr}_{1}$ & 2738.08 & 104 & 3.22 & 0.91 \\
$\mathrm{U}_{127} \mathrm{I}_{1}$ & 2745.50 & 101 & 4.12 & 2.03 \\
$\mathrm{U}_{127} \mathrm{Cs}_{1}$ & 2755.23 & 98 & 3.33 & 5.24 \\
$\mathrm{U}_{127} \mathrm{Pu}_{1}$ & 2730.82 & 102 & 4.34 & 0.24 \\
\hline \hline
\end{tabular}


from our MD simulation, compared to $1.33 \mathrm{eV}$ from the sm calculation (Table II), is apparently not in better agreement with the positron spectroscopy estimate $(1 \mathrm{eV})$. But Matter et al. have pointed out that their positron annihilation coincident count rate experiment was not accurate for uranium. Later Kogel et al. have studied vacancy formation and phase transformations in uranium through positron lifetime and Doppler broadening measurements [68]. They stated that their positron lifetime measurements enable more accurate estimates of positrons trapped at vacancies than the coincident count rate employed by Matter et al. [67]. They reported that the average formation enthalpy of vacancy in bcc uranium is of the order of $0.3 \mathrm{eV}$. This is quite different from the Matter et al. value $(1 \mathrm{eV})$.

Recently, Lund et al. have investigated the effect of impurities on the vacancy formation enthalpy in uranium using DFT calculations and Doppler broadening of positron annihilation radiation [69]. They obtained $1.6 \pm 0.2 \mathrm{eV}$ for the vacancy formation energy. They reported that the lower values obtained in previous measurements were due to oxygen impurities contained in the samples. But it is not clear whether their experimental result is for bcc or orthorhombic uranium because they compare it with the DFT result obtained for the orthorhombic phase. (Our vacancy formation energy of orthorhombic uranium, $1.84 \mathrm{eV}$, from the conventional DFT total energy calculation is in good agreement with their DFT result.) On the other hand, earlier experimental studies $[67,68]$ were for the bcc phase. This means that the measured vacancy formation energy of bcc uranium remains uncertain. In view of this, and in view of the acceptable performance of our computational scheme for $\mathrm{Zr}$ and $\mathrm{W}$, we think that the $0.88 \mathrm{eV}$ for the vacancy formation energy from our MD simulation is more reliable.

For solute $\mathrm{Zr}$, our molecular dynamics simulation gives a formation energy of $0.91 \mathrm{eV}$, which is higher than that obtained from the sm (Table II). The formation energy of $\mathrm{Zr}$ solute from our MD simulation is more reliable because the equilibrium volume of $\mathrm{U}_{128}$ and hence that of $\mathrm{U}_{127} \mathrm{Zr}_{1}$ from MD are in better agreement with experiment than those from the sm. For the formation energies of other solutes, neither first-principles MD nor experimental results are available in the literature. But we note that the equilibrium volumes of $\mathrm{U}_{127} \mathrm{M}_{1}$ given in Tables II and IV are about the respective equilibrium volumes of $\mathrm{U}_{128}$, which are 2574.78 and $2731.43 \AA^{3}$, respectively. The lower volume corresponds to room temperature, where bcc uranium is unstable. Therefore, the formation energies of $\mathrm{M}$ in a bcc uranium matrix obtained from the sm is not reliable. The formation energy of solute $\mathrm{Pu}$ in bcc $\mathrm{U}(0.24 \mathrm{eV})$ is the lowest among the solutes considered here. Note that this corresponds to the total energy of $\mathrm{Pu}$ at its experimental lattice constants. DFT relaxation typically lowers the total energy of a crystal by a few electron volts. This means that the formation energy of $\mathrm{Pu}$ in bcc $\mathrm{U}$ will increase by about $0.1 \mathrm{eV}$. That is, the formation energy of $\mathrm{Pu}$ solute in bcc $\mathrm{U}$ will increase to $0.34 \mathrm{eV}$. Even then the formation energy of solute $\mathrm{Pu}$ is lowest. This is reasonable because $\mathrm{Pu}$ is readily soluble in bcc $\mathrm{U}$ and the addition of $\mathrm{Pu}$ (melting point, $913 \mathrm{~K}$ ) to uranium (melting point, $1408 \mathrm{~K}$ ) causes the melting point of uranium alloys to decrease substantially.

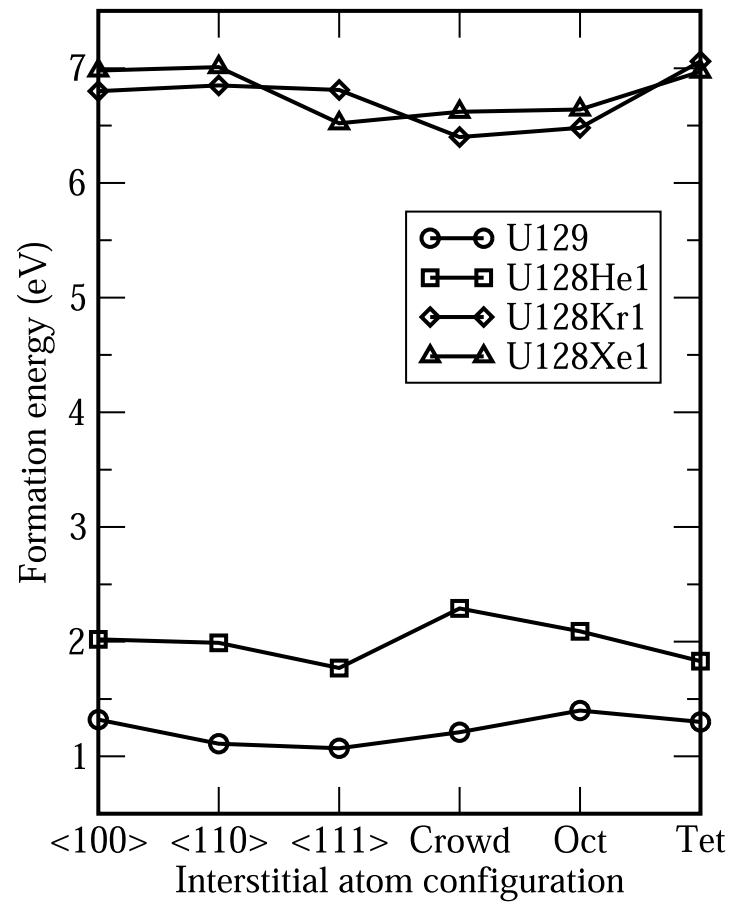

FIG. 6. Self and solute interstitial formation energies in bcc U as a function of the interstitial configuration. The $x$-axis labels Crowd, Oct, and Tet correspond, respectively, to crowdion, octahedral, and tetrahedral dumbbell configurations.

Table $\mathrm{V}$ lists the set of formation energies of self and solute interstitials ( $E_{f}^{\text {sia }}$ and $\left.E_{f}^{\text {oia }}\right)$ considered in this work. The equilibrium volumes listed here show similarity to the respective volumes of uranium without and with substitutional solutes listed in Table IV. That is, the equilibrium volumes show a correspondence to the size of the solute or impurity atoms $\mathrm{M}$. The equilibrium volumes in Table $\mathrm{V}$ are enhanced relative to those in Table IV, reflecting the increase in the number of atoms. Figure 6 illustrates the self and solute interstitial formation energies in bcc uranium for the six basic interstitial configurations. It is evident that the self interstitial atom formation energies are lower than those of solute interstitial atoms. That is, bcc $\mathrm{U}$ accommodates self interstitials more easily than decay or fission gas interstitials $(\mathrm{He}, \mathrm{Kr}, \mathrm{Xe})$.

The minimum self interstitial formation energy of $1.07 \mathrm{eV}$ $(\langle 111\rangle$ configuration) is higher than the vacancy formation energy of $0.88 \mathrm{eV}$ (Table IV). This indicates that vacancies are favorable point defects in bcc uranium rather than both vacancies and self interstitials, in comparable amounts, as reported in earlier works [25-27]. This variance with the literature is because they are based on either the sm or the embedded atom method potentials constructed using results of the shell method, which has inherent limitations [25,26].

In Tables IV and $\mathrm{V}$, it is further evident that $\mathrm{He}$ atoms have comparable formation energies in substitutional and interstitial locations. The fission product atoms $\mathrm{Kr}$ and $\mathrm{Xe}$ prefer to occupy vacant substitutional lattice sites rather than interstitial sites.

The formation energies of noble gas atoms in Table IV show that they bear a relation to the size of solute atoms. $\mathrm{He}$ is a relatively small atom. The solute formation energy 
TABLE V. Properties of bcc uranium with self and solute interstitials obtained from ab initio molecular dynamics simulations at $1100 \mathrm{~K}$. The equilibrium volumes $(P=0)$ of the simulation supercells, $V_{0}$, together with the formation energies of interstitial defects $\left(E_{\mathrm{sia}}^{f}\right.$ or $\left.E_{\mathrm{oia}}^{f}\right)$ in six different configurations in bcc uranium are given. Estimates of the bulk moduli, $B_{0}$, and thermal volume expansion coefficients, $\alpha$, of these systems are also listed.

\begin{tabular}{|c|c|c|c|c|c|}
\hline System & Configuration & $V_{0}\left(\AA^{3}\right)$ & $B_{0}(\mathrm{GPa})$ & $10^{-5} \alpha(1 / \mathrm{K})$ & $E_{\text {sia }}^{f}, E_{\text {oia }}^{f}(\mathrm{eV})$ \\
\hline \multirow{6}{*}{$\mathrm{U}_{129}$} & $\langle 100\rangle$ & 2760.07 & 107 & 4.68 & 1.32 \\
\hline & $\langle 110\rangle$ & 2757.57 & 109 & 2.80 & 1.11 \\
\hline & $\langle 111\rangle$ & 2757.88 & 109 & 4.31 & 1.07 \\
\hline & Crowdion & 2757.40 & 109 & 4.46 & 1.21 \\
\hline & Octahedral & 2758.40 & 109 & 3.02 & 1.40 \\
\hline & Tetrahedral & 2757.98 & 111 & 2.93 & 1.30 \\
\hline \multirow[t]{6}{*}{$\mathrm{U}_{128} \mathrm{He}_{1}$} & $\langle 100\rangle$ & 2751.73 & 105 & 2.87 & 2.02 \\
\hline & $\langle 110\rangle$ & 2752.61 & 103 & 4.66 & 1.99 \\
\hline & $\langle 111\rangle$ & 2751.03 & 107 & 3.24 & 1.77 \\
\hline & Crowdion & 2752.07 & 105 & 3.25 & 2.29 \\
\hline & Octahedral & 2751.11 & 105 & 2.96 & 2.09 \\
\hline & Tetrahedral & 2751.19 & 104 & 3.88 & 1.83 \\
\hline \multirow[t]{6}{*}{$\mathrm{U}_{128} \mathrm{Kr}_{1}$} & $\langle 100\rangle$ & 2770.92 & 109 & 2.85 & 6.80 \\
\hline & $\langle 110\rangle$ & 2770.52 & 107 & 2.27 & 6.85 \\
\hline & $\langle 111\rangle$ & 2770.62 & 108 & 3.63 & 6.81 \\
\hline & Crowdion & 2770.58 & 108 & 5.47 & 6.40 \\
\hline & Octahedral & 2769.50 & 109 & 4.12 & 6.48 \\
\hline & Tetrahedral & 2768.62 & 111 & 2.31 & 6.29 \\
\hline \multirow[t]{6}{*}{$\mathrm{U}_{128} \mathrm{Xe}_{1}$} & $\langle 100\rangle$ & 2775.21 & 109 & 3.16 & 6.98 \\
\hline & $\langle 110\rangle$ & 2775.20 & 109 & 6.80 & 7.01 \\
\hline & $\langle 111\rangle$ & 2772.80 & 113 & 2.48 & 6.52 \\
\hline & Crowdion & 2774.61 & 111 & 5.22 & 6.62 \\
\hline & Octahedral & 2773.89 & 113 & 3.48 & 6.64 \\
\hline & Tetrahedral & 2774.91 & 109 & 3.44 & 6.97 \\
\hline
\end{tabular}

of $\mathrm{He}$ is low. Xe is relatively large. It has a high formation energy. This size effect of noble gas elements on their formation energies is also evident from the interstitial formation energies given in Table V and Fig. 6. Our MD simulation of interstitial Xe shows that it has the lowest formation energy, $6.52 \mathrm{eV}$, in the $\langle 111\rangle$ configuration. This is comparable to its substitutional formation energy of $6.46 \mathrm{eV}$. These are quite different compared to the corresponding energies of 10.08 and $5.54 \mathrm{eV}$ reported by Beeler et al. using the sm [26]. Our work thus predicts that the substitutional and $\langle 111\rangle$ interstitial Xe defects form with comparable probabilities. Note that the volumes of $\mathrm{Xe}$ in these configurations are comparable.

The apparent size effect on the point defect formation energies of noble gas elements is not quite evident for other solutes, namely, $\mathrm{Sr}, \mathrm{Zr}, \mathrm{I}, \mathrm{Cs}$, and $\mathrm{Pu}$. Since these elements are chemically reactive, their formation energies in uranium appear to be influenced by both size and chemical effects.

Table IV also lists the bulk moduli, $B_{0}$, and volume thermal expansion coefficients, $\alpha$. The bulk modulus of $109 \mathrm{GPa}$ for pure uranium is in good agreement with the experimental value of $113 \mathrm{GPa}$ [20]. We see further that the bulk moduli of uranium with point defects tend to be reduced compared to that of pure uranium. These reductions in bulk moduli are similar to the reduction of the bulk moduli of bcc $\mathrm{W}$ due to inert gas atom defects [59]. The bulk moduli of uranium with self and solute interstitials, given in Table V, are of the same order as those of uranium with substitutional solutes or impurities given in Table IV. It is difficult to distinguish between substitutional and interstitial solutes from their effect on the bulk modulus of uranium.

The thermal expansion coefficient is one of the important properties in fuel pin design and performance modeling. For instance, an increase in fuel volume and associated decrease in density due to thermal expansion can cause enhanced neutron leakage and hence negative feedback [70]. Therefore, it is important to understand the influence of point defects on the thermal expansion coefficient. We see in Table IV that the volume thermal expansion coefficient of pure bcc uranium obtained from our MD simulation $\left(2.21 \times 10^{-5} / \mathrm{K}\right)$ is in very good agreement with the experimental value $\left(2.46 \times 10^{-5} / \mathrm{K}\right)$ of Yoo et al. [20]. This allows us to assume that our calculated thermal expansion coefficients of other systems are useful estimates. It is evident that the thermal expansion coefficients of uranium with point defects (Tables IV and V) are generally increased substantially relative to that of pure bcc uranium. Our supercell model corresponds to point defect concentrations of less than $1.6 \%$. The thermal expansion coefficient of bcc uranium with this point defect concentration is not found in the literature. Dilatometry curves obtained for uranium alloy with 2 to $10 \mathrm{wt} \% \mathrm{Zr}$ show that the thermal expansion increases with $\mathrm{Zr}$ addition [71], which is in agreement with our increased thermal expansion coefficient of $U_{127} Z_{1}$ relative to that of pure bcc uranium.

A theory of thermal expansion of crystals containing substitutional point defects exists in the literature [72]. But its validation is not common. This theory split atomic displacements into a sum of dynamic displacements, a homogeneous 
TABLE VI. Properties of $\mathrm{U}_{126} \mathrm{M}_{1} \square_{1}(\mathrm{M}=\square$, He, Ne, Ar, Kr, $\mathrm{Xe}, \mathrm{Sr}, \mathrm{Zr}, \mathrm{I}, \mathrm{Cs}, \mathrm{Pu})$ obtained from $a b$ initio molecular dynamics simulation at $1100 \mathrm{~K}$. The equilibrium volumes $(P=0)$ of the simulation supercells, $V_{0}$, together with the binding energies, $E^{b}$, of atomic defects in bcc uranium are given. Estimates of the bulk moduli, $B_{0}$, and thermal volume expansion coefficients, $\alpha$, of these systems are also listed.

\begin{tabular}{lcccc}
\hline \hline System & $V_{0}\left(\AA^{3}\right)$ & $B_{0}(\mathrm{GPa})$ & $10^{-5} \alpha(1 / \mathrm{K})$ & $E^{b}(\mathrm{eV})$ \\
\hline $\mathrm{U}_{126} \square_{1} \square_{1}$ & 2702.23 & 104 & 3.65 & +0.31 \\
$\mathrm{U}_{126} \mathrm{He}_{1} \square_{1}$ & 2713.66 & 99 & 4.20 & -0.37 \\
$\mathrm{U}_{126} \mathrm{Ne}_{1} \square_{1}$ & 2719.66 & 97 & 3.81 & -0.22 \\
$\mathrm{U}_{126} \mathrm{Ar}_{1} \square_{1}$ & 2721.90 & 100 & 4.12 & -0.18 \\
$\mathrm{U}_{126} \mathrm{Kr}_{1} \square_{1}$ & 2729.94 & 104 & 2.89 & -0.36 \\
$\mathrm{U}_{126} \mathrm{Xe}_{1} \square_{1}$ & 2735.06 & 103 & 1.84 & -0.69 \\
$\mathrm{U}_{126} \mathrm{Sr}_{1} \square_{1}$ & 2738.23 & 93 & 4.75 & -0.52 \\
$\mathrm{U}_{126} \mathrm{Zr}_{1} \square_{1}$ & 2719.90 & 103 & 3.83 & -0.23 \\
$\mathrm{U}_{126} \mathrm{I}_{1} \square_{1}$ & 2729.04 & 103 & 2.65 & -0.85 \\
$\mathrm{U}_{126} \mathrm{Cs}_{1} \square_{1}$ & 2738.95 & 102 & 2.65 & -0.64 \\
$\mathrm{U}_{126} \mathrm{Pu}_{1} \square_{1}$ & 2712.21 & 100 & 4.68 & -0.46 \\
\hline \hline
\end{tabular}

strain, and a local strain near the defects. Figure 5 and Figs. S2, S4, S6, and S8 in the Supplemental Material [64] suggest that the average mean square displacements in $\mathrm{U}_{127} \mathrm{M}_{1}$ and $\mathrm{U}_{128} \mathrm{M}_{1}$ are greater than that in $\mathrm{U}_{128}$. This allows us to think that the solute elements make uranium matrix less stiff leading to the enhanced thermal expansion coefficients of $\mathrm{U}_{127} \mathrm{M}_{1}$ and $\mathrm{U}_{128} \mathrm{M}_{1}$ in Tables IV and $\mathrm{V}$. This interpretation is, however, not quite true for some of the substitutional solutes such as Ne, Ar, and Sr. Smirnov and Stegailov [27], through comparison of the formation energies of vacancy and self interstitial and the thermal expansion coefficients of pure Mo and $U$ crystals, hypothesized that a defect-based mechanism of thermal expansion should be significant in bcc uranium. Our thermal expansion coefficients in Tables IV and V appear to support this hypothesis.

\section{Solute-vacancy defect pairs in bcc uranium}

As discussed in Sec. I, the binding energies of solutes to vacancies determine their diffusion kinetics. Therefore, we have also performed $\mathrm{MD}$ simulations of $\mathrm{U}_{126} \mathrm{M}_{1} \square_{1}(\mathrm{M}=\square$, $\mathrm{He}, \mathrm{Ne}, \mathrm{Ar}, \mathrm{Kr}, \mathrm{Xe}, \mathrm{Sr}, \mathrm{Zr}, \mathrm{I}, \mathrm{Cs}, \mathrm{Pu}$ ) to compute the M- $\square$ binding energies. Plots of the position auto correlations and the mean square displacements in $\mathrm{U}_{126} \mathrm{M}_{1} \square_{1}$ from our MD simulations are provided in the Supplemental Material (Figs. S9 and S10) [64]. These plots show that the PACs decrease to 0 . This decrease is somewhat slow in $\mathrm{U}_{126} \square_{1} \square_{1}$. The MSDs become constant with time and are smaller than half the nearest-neighbor bond lengths of these systems (2.96 $\AA$ ). This behavior of PACs and MSDs suggests that the systems remain in the same bcc structure of uranium during the simulations.

The equilibrium energies of each of these systems were then obtained in the same manner as described earlier. These energies were then used in the calculations of the M- $\square$ binding energies. Table VI lists these binding energies $E^{b}$ together with the equilibrium volumes of the simulation supercells. Estimates of the bulk moduli and thermal volume expansion coefficients of these systems are also listed.
The equilibrium volumes of $\mathrm{U}_{126} \mathrm{M}_{1} \square_{1}$ are reduced relative to the respective equilibrium volumes of $\mathrm{U}_{127} \mathrm{M}_{1}$ (Table IV) for all M's. The reductions in volume vary from 14 to 19 $\AA^{3}$, which is comparable to the atomic volume of uranium $\left(20.84 \AA^{3}\right)$. The corresponding volumes from the sm (Table II) vary from -9 to $36 \AA^{3}$, which deviate significantly from the atomic volume of uranium. Thus, the equilibrium volumes and hence formation and binding energies of point defects in bcc uranium obtained from our molecular dynamics simulation are more reliable than those from the shell method. Further, the bulk moduli of $\mathrm{U}_{126} \mathrm{M}_{1} \square_{1}$ tend to be reduced relative to those of respective $\mathrm{U}_{127} \mathrm{M}_{1}$. For instance, the $B_{0}$ values of $\mathrm{U}_{127} \square_{1}, \mathrm{U}_{127} \mathrm{He}_{1}$, and $\mathrm{U}_{126} \mathrm{He}_{1} \square_{1}$ are, respectively, 102, 103 , and $99 \mathrm{GPa}$. That is, the $B_{0}$ of $\mathrm{U}_{126} \mathrm{He}_{1} \square_{1}$ is lower than those of $\mathrm{U}_{127} \square_{1}$ and $\mathrm{U}_{127} \mathrm{He}_{1}$. This appears reasonable. But there are exceptions. For instance, the $B_{0}$ values of $\mathrm{U}_{127} \mathrm{Cs}_{1}$ and $\mathrm{U}_{126} \mathrm{Cs}_{1} \square_{1}$ (98 and $102 \mathrm{GPa}$ ) with reference to that of $\mathrm{U}_{127} \square_{1}$ do not maintain the same trend, though their PAC and MSD are quite fine. The above trend is also not maintained between $\mathrm{U}_{127} \square_{1}$ and $\mathrm{U}_{126} \square_{1} \square_{1}$. Thus the $B_{0}$ 's are to be considered as representative values. Quantitative comparison would require more accurate simulations with more $P-V$ points, which are quite difficult due to limitation of computer resources.

The M- $\square$ binding energies from MD simulations given in Table VI are generally less exothermic $(-0.18$ to $-0.69 \mathrm{eV})$ compared to those from the sm $(-2.41$ to $-3.62 \mathrm{eV}$ in Table II). This is acceptable because such binding energies in bcc iron [18] are generally higher than $-1.5 \mathrm{eV}$ and because our binding energies are similar to the He- $\square$ binding in tungsten [59]. Our divacancy binding energy of $0.31 \mathrm{eV}$ is similar to the $0.30 \mathrm{eV}$ in iron [73]. Our solute-vacancy and divacancy binding energies thus suggest that nucleation and growth of fission gas bubbles are supported by a thermodynamic driving force which is absent for void formation from joining of vacancies. This is in agreement with Li et al., who have reported that, at high temperatures, bcc uranium softens and swells mainly by agglomeration of noble gas bubbles [74].

\section{Error estimation}

Due to the scarcity of literature on the properties of bcc uranium with point defects, a full comparison of our results is not possible. A brief consideration of the various sources of errors in our MD simulation of point defect energies is therefore given here to estimate the accuracy of our results. Freysoldt et al. [12] have provided a broad review of the various sources of error in the first-principles calculations of point defects in solids. We chose the PAW method with the PBE exchange correlation functional, which is more accurate than other pseudopotentials and exchange correlation functionals [12]. A $4 \times 4 \times 4$ bcc supercell with 128 lattice sites has been reported to be sufficient to obtain converged results from MD simulation of uranium for the equation of state, the Gruneisen parameter and specific heat, and the radial and bond-angle distribution functions [28]. Further, Puska et al. have investigated the convergence of supercell calculations for point defects in semiconductors [75]. This work shows that a cubic supercell of 128 atoms with $\Gamma k$-point Brillouin zone sampling gives the converged point defect formation energy. They have also suggested that supercell convergence can be 
achieved with a relatively smaller cell for point defects in metals. Moreover, the defect formation energies are defined as an energy difference between supercell calculations with and without a defect [Eqs. (1)-(4)]. The energy difference between two similar systems is much more rapidly convergent due to the cancellation of systematic errors $[12,76]$. This convergence is often seen in the formation energies of point defects. Since a consistent supercell size and $k$-point sampling have been used in the present work, we assume that the errors due to supercell size and $k$-mesh convergence are negligible.

We turn next to the error bar due to the fluctuation of the energy of the systems during MD simulations. After thermalization, the energies of all systems were fluctuating with a standard deviation of about $0.11 \%$ from the mean. These fluctuations lead to a maximum error bar of $\pm 0.12 \mathrm{eV}$ in the formation and binding energies reported in this work. It is worthwhile to consider the influence of this error on the point defect energies. This error is smaller than the difference in the formation energies of $\mathrm{Kr}$ and $\mathrm{Xe}$, for instance (Table IV), whereas it is larger than the difference in the formation energies of the vacancy and the solute Zr. Similarly, the error is smaller than the difference in the formation energies of different types of interstitials, namely, between pure and mixed dumbbells (Table V), whereas it is larger than the difference in the formation energies between different configurations of the dumbbells. This leads to an ambiguity in identifying, for instance, the most favored dumbbell configuration or the favored point defect between the vacancy and Zr. These scenarios, however, cannot be attributed entirely to errors in simulations because the point defect formation energies presented here pertain to a given temperature, and they are reported to have different temperature dependences $[12,77,78]$.

Lucas and Schaublin have investigated vacancies and self interstitials in bcc iron [77]. Their work shows that (Fig. 3 in [77]) the free energy of formation of the $\langle 110\rangle$ dumbbell is almost constant in the temperature range 0 to $1000 \mathrm{~K}$, whereas the free energies of formation of the $\langle 111\rangle$ dumbbell and the vacancy vary considerably with the temperature. With respect to the $\langle 110\rangle$ dumbbell, the temperature-dependent variations of the $\langle 111\rangle$ dumbbell and vacancy are opposite. This means that point defect formation energies show significantly different temperature dependences, and thus the error bars are not fixed. Moreover, Kobelev and Khonik have shown that the nonlinear behavior of the Gibbs energy of formation for point defects is due to the nonlinear temperature dependence of their formation enthalpy [78] rather than formation entropy [12]. This dependence is argued to originate from the temperature dependence of the shear modulus and related shear field created by point defects.

A brief account of the formation entropy is also given. Although most defect studies are based on the formation en$\operatorname{ergy} E^{\mathrm{f}}$, for the calculation of equilibrium concentrations of point defects, their free energies of formation are more pertinent [12]. Thermodynamic integration technique combined with MD simulations can be used to compute the free energy of formation [43-45]. This requires heavy computational resources. We have therefore used MD simulations to obtain the equilibrium energies at a given temperature rather than free energies. That is, our formation energies omit the entropy of point defect formation.

The vibrational contributions to the free formation energy of point defects (vacancy, $\mathrm{Cu}, \mathrm{Y}, \mathrm{Ti}, \mathrm{Cr}, \mathrm{Mn}, \mathrm{Ni}, \mathrm{V}, \mathrm{Mo}, \mathrm{Si}$, $\mathrm{Al}, \mathrm{Co}, \mathrm{O})$ in bcc iron have been reported by Murali et al. recently. This work shows that the vibrational entropy of point defect formation ranges from 0.05 to $3.0 k_{B}$ for Co and vacancy defects, respectively (except vanadium, which has a negative entropy of formation) [33,79]. This means that the vibrational contribution would lower the formation energy of point defects in bcc iron by up to $0.25 \mathrm{eV}$ at $1000 \mathrm{~K}$. The formation entropy of dumbbells in $\mathrm{Na}$ is suggested to be about $7 k_{B}$ [44]. Further, Nordlund and Averback have reviewed the calculation of point defect properties in metals [80]. Their article reports that the formation entropy of interstitials in FCC metals can be as high as $15 k_{B}$. This translates to a lowering of the interstitial formation energies of FCC metals by up to $1.42 \mathrm{eV}$ at $1100 \mathrm{~K}$. If we assume such entropy contributions in bcc uranium, a similar lowering of the formation energies of point defects can be expected.

\section{SUMMARY AND CONCLUSIONS}

First-principles molecular dynamics simulations have been carried out to calculate the thermodynamic properties of bcc uranium with point defects. BCC uranium is a hightemperature phase known as $\gamma$ uranium. The simulations were performed at $1100 \mathrm{~K}$ with canonical ensembles of $\mathrm{U}_{127} \mathrm{M}_{1}$, $\mathrm{U}_{128} \mathrm{M}_{1}$, and $\mathrm{U}_{126} \mathrm{M}_{1} \square_{1}$ disposed on a bcc lattice lying within a $4 \times 4 \times 4$ cubic cell. This work provides the formation and binding energies of different types of point defects, namely, substitutional defects, self and solute interstitial dumbbell defects, and M- $\square$ pair defects for $\mathrm{M}=\square$, He, Ne, Ar, Kr, Xe, Sr, $\mathrm{Zr}$, I, Cs, and Pu. Equilibrium volumes, bulk moduli, and thermal expansion coefficients of bcc uranium with these point defects are also reported. This work demonstrates that molecular dynamics simulations give reliable equilibrium volumes, formation energies, and binding energies of atomic defects in bcc uranium compared to conventional DFT calculations. The equilibrium volume, bulk modulus, and thermal expansion coefficient of pure bcc uranium obtained from our computational scheme based on canonical ensemble MD simulations compare very well with corresponding experimental results. Our MD simulations predict a vacancy formation energy of $0.88 \mathrm{eV}$. The experimental vacancy formation energy of bcc uranium remains uncertain. Experimental study of the formation and binding energies of other point defects is also not found in the literature. This work shows that point defects tend to decrease the bulk modulus and increase the thermal expansion coefficient of bcc uranium. Experimental bulk modulus and thermal expansion coefficients of bcc uranium with these point defects are also absent from the literature.

The solute formation energies of noble gas atoms show a relation to their size. A large solute $(\mathrm{Xe})$ has a high formation energy, and vice versa. This size effect is not quite evident for other solutes, namely, $\mathrm{Sr}, \mathrm{Zr}, \mathrm{I}, \mathrm{Cs}$, and $\mathrm{Pu}$. Since these elements are chemically reactive, their formation energies in uranium appear to be influenced by both size and chemistry. Our MD simulations further show that vacancies are favorable point defects in bcc uranium rather than both vacancies and 
self interstitials as predicted by earlier calculations. This work also shows that self interstitial atom formation energies are lower than those of solute interstitial atoms, both calculated in six different basic interstitial dumbbell configurations. That is, bcc $\mathrm{U}$ accommodates self interstitials more easily than decay or fission gas interstitials $(\mathrm{He}, \mathrm{Kr}$, or $\mathrm{Xe}$ ). Further, $\mathrm{He}$ atoms have comparable formation energies in substitutional and interstitial configurations. The fission product atoms $\mathrm{Kr}$ and Xe prefer to occupy vacant substitutional lattice sites rather than interstitial sites. The binding energies of divacancy and solute-vacancy pairs $(0.31 \mathrm{vs}-0.69 \mathrm{eV}$ for the $\mathrm{Xe}-\square$ pair, for instance) from our MD simulation show that nucle- ation and growth of fission gas bubbles are supported by a thermodynamic driving force, whereas vacancies tend to stay separated. This is in agreement with literature reporting that bcc uranium softens and swells mainly by agglomeration of noble gas bubbles.

\section{ACKNOWLEDGMENTS}

The authors acknowledge the fruitful discussion with Dr. R. Rajaraman and Dr. T. R. Ravindran and the computing systems section of IGCAR for the high-performance parallel computing cluster computer facility.
[1] C. V. Sundaram and S. L. Mannan, Sadhana 14, 21 (1989).

[2] J. H. Kittel, B. R. T. Frost, J. P. Mustelier, K. Q. Bagley, G. C. Crittenden, and J. van Dievoet, J. Nucl. Mater. 204, 1 (1993).

[3] J. R. Lamarsh and A. J. Baratta, Introduction to Nuclear Engineering (Prentice Hall, Hoboken, NJ, 2001).

[4] B. Raj, M. Vijayalakshmi, P. R. V. Rao, and K. B. S. Rao, MRS Bull. 33, 327 (2008).

[5] D. Andersson, in Handbook of Materials Modeling, edited by W. Andreoni and S. Yip (Springer, Cham, Switzerland, 2018).

[6] W. J. Carmack, D. L. Porter, Y. I. Chang, S. L. Hayes, M. K. Meyer, D. E. Burkes, C. B. Lee, T. Mizuno, F. Delage, and J. Somers, J. Nucl. Mater. 392, 139 (2009).

[7] A. M. Adamska, R. Springell, and T. B. Scott, Thin Solid Films 550, 319 (2014).

[8] K. Santu, B. Joydipta, S. C. Parida, and B. Vivek, J. Nucl. Mater. 504, 234 (2018).

[9] Y. Guérin, G. S. Was, and S. J. Zinkle, MRS Bull. 34, 10 (2009).

[10] S. J. Zinkle and G. S. Was, Acta Mater. 61, 735 (2013).

[11] C. G. Van de Walle, in Encyclopedia of Materials: Science and Technology, 2nd ed., edited by K. H. J. Buschow (Elsevier, Amsterdam, 2001), p. 7125.

[12] C. Freysoldt, B. Grabowski, T. Hickel, J. Neugebaur, G. Kresse, A. Janotti, and C. G. Van de Walle, Rev. Mod. Phys. 86, 253 (2014).

[13] C. D. Versteylen, N. H. van Dijk, and M. H. F. Sluiter, Phys. Rev. B 96, 094105 (2017).

[14] S. Pogatscher, H. Antrekowitsch, M. Werinos, F. Moszner, S. S. A. Gerstl, M. F. Francis, W. A. Curtin, J. F. Loffler, and P. J. Uggowitzer, Phys. Rev. Lett. 112, 225701 (2014).

[15] D. Shin and C. Wolverton, Acta Mater. 58, 531 (2010).

[16] C. Toffolon-Masclet, A. Perron, B. Mazeres, S. Depinoy, C. Desgranges, L. Martinelli, D. Monceau, X. Boulnat, A. Mathevon, and M. Perez, in Comprehensive Nuclear Materials, 2nd ed., edited by R. Konings and R. Stoller (Elsevier, Amsterdam, 2020), Vol. 1, p. 850.

[17] L. Ferry, F. Virot, M. Barrachin, Y. Ferro, C. Pardanaud, D. Matveev, M. Wensing, T. Dittmar, M. Koppen, and C. Linsmeier, Nucl. Mater. Energy 12, 453 (2017).

[18] E. A. Devi, C. Ravi, and C. S. Sundar, Phys. Rev. B 98, 144104 (2018).

[19] C. Wolverton, Acta Mater. 55, 5867 (2007).

[20] C.-S. Yoo, H. Cynn, and P. Soderlind, Phys. Rev. B 57, 10359 (1998).
[21] L. Leibowitz and R. A. Blomquist, J. Nucl. Mater. 167, 76 (1989).

[22] P. Soderlind, B. Grabowski, L. Yang, A. Landa, T. Bjorkman, P. Souvatzis, and O. Eriksson, Phys. Rev. B 85, 060301(R) (2012).

[23] W. Xiong, W. Xie, C. Shen, and D. Morgan, J. Nucl. Mater. 443, 331 (2013).

[24] A. P. Moore, C. Deo, M. I. Baskes, and M. A. Okuniewski, Acta Mater. 115, 178 (2016).

[25] B. Beeler, B. Good, S. Rashkeev, C. Deo, M. Baskes, and M. Okuniewski, J. Phys.: Condens. Matter 22, 505703 (2010).

[26] B. Beeler, B. Good, S. Rashkeev, C. Deo, M. Baskes, and M. Okuniewski, J. Nucl. Mater. 425, 2 (2012).

[27] G. S. Smirnov and V. V. Stegailov, J. Phys.: Condens. Matter 31, 235704 (2019).

[28] R. Q. Hood, L. H. Yang, and J. A. Moriarty, Phys. Rev. B 78, 024116 (2008).

[29] R. W. Grimes, in Fundamental Aspects of Inert Gases in Solids edited by S. E. Donnelly and J. H. Evans (Plenum Press, New York, 1991), p. 415.

[30] A. E. Thompson and C. Wolverton, Phys. Rev. B 84, 13411 (2011).

[31] S. Han, L. A. Zepeda-Ruiz, G. J. Ackland, R. Car, and D. J. Srolovitz, Phys. Rev. B 66, 220101(R) (2002).

[32] T. Suzudo, M. Yamaguchi, and A. Hasegawa, Model. Simul. Mater. Sci. Eng. 22, 075006 (2014).

[33] D. Murali, M. Posselt, and M. Schiwarth, Phys. Rev. B 92, 064103 (2015).

[34] G. Kresse and J. Hafner, Phys. Rev. B 47, 558 (1993).

[35] G. Kresse and J. Furthmuller, Phys. Rev. B 54, 11169 (1996).

[36] P. E. Blochl, Phys. Rev. B 50, 17953 (1994).

[37] G. Kresse and D. Joubert, Phys. Rev. B 59, 1758 (1999).

[38] J. P. Perdew, K. Burke, and M. Ernzerhof, Phys. Rev. Lett. 77, 3865 (1996).

[39] M. Methfessel and A. T. Paxton, Phys. Rev. B 40, 3616 (1989).

[40] H. C. Andersen, J. Chem. Phys. 72, 2384 (1980).

[41] D. Frenkel and B. Smit, Understanding Molecular Simulation from Algorithms to Applications, 2nd ed. (Academic Press, San Diego, CA, 2002).

[42] F. Buda, G. L. Chiarotti, R. Car, and M. Parrinello, Phys. Rev. Lett. 63, 294 (1989).

[43] V. Milman, M. C. Payne, V. Heine, R. J. Needs, J. S. Lin, and M. H. Lee, Phys. Rev. Lett. 70, 2928 (1993). 
[44] E. Smargiassi and P. A. Madden, Phys. Rev. B 51, 129 (1995).

[45] G. A. de Wijs, G. Kresse, and M. J. Gillan, Phys. Rev. B 57, 8223 (1998).

[46] B. Fultz, Prog. Mater. Sci. 55, 247 (2010).

[47] D. Alfe, Comput. Phys. Commun. 118, 31 (1999).

[48] P. Villars, Pauling File, Inorganic Solid Phases (Springer, Berlin, Heidelberg, 2016).

[49] P. Soderlind, A. Landa, and B. Sadigh, Adv. Phys. 68, 1 (2019).

[50] Y. Zhang and Z. Xu, Am. Mineral. 80, 670 (1995).

[51] C. Kittel, Introduction to Solid State Physics, 7th ed. (John Wiley \& Sons, New York, 1995).

[52] L. Vocadlo, D. Alfe, M. J. Gillan, I. G. Wood, J. P. Brodholt, and G. D. Pirce, Nature 424, 536 (2003).

[53] J. M. Haile, Molecular Dynamics Simulation (John Wiley \& Sons, New York, 1992).

[54] Y. Zhao et al., Phys. Rev. B 71, 184119 (2005).

[55] A. Heiming, W. Petry, J. Trampenau, M. Alba, C. Herzig, H. R. Schober, and G. Vogl, Phys. Rev. B 43, 10948 (1991).

[56] B. Skinner and H. L. Johnston, J. Chem. Phys. 21, 1383 (1953).

[57] G. Neumann, V. Tolle, and C. Tuijn, Physica B 296, 334 (2001).

[58] D. Nguyen-Manh, A. P. Horsfield, and S. L. Dudarev, Phys. Rev. B 73, 020101(R) (2006).

[59] D. Nguyen-Manh and S. L. Dudarev, Nucl. Instrum. Methods Phys. Res. B 352, 86 (2015).

[60] R. A. MacDonald and R. C. Shukla, Phys. Rev. B 32, 4961 (1985).

[61] P. I. Dorogokupets, E. M. Ponomarev, and E. A. Melekhova, Petrology 7, 574 (1999).

[62] ASM International, ASM Ready Reference: Thermal Properties of Metals (ASM International, Almere, Netherlands, 2002).

[63] P. Tolias and the EUROfusion MST1 Team, Nucl. Mater. Energy 13, 42 (2017).
[64] See Supplemental Material at http://link.aps.org/supplemental/ 10.1103/PhysRevMaterials.5.053604 for position autocorrelations and mean squared displacements in $\mathrm{U}_{129}, \mathrm{U}_{128} \mathrm{He}_{1}$, $\mathrm{U}_{128} \mathrm{Kr}_{1}, \mathrm{U}_{128} \mathrm{Xe}_{1}$ and $\mathrm{U}_{126} \mathrm{M}_{1} \square_{1}$.

[65] Y. G. Hao, O. Eriksson, G. W. Fernando, and B. R. Cooper, Phys. Rev. B 47, 6680 (1993).

[66] G. H. Lander, J. Magn. Magn. Mater. 29, 271 (1982).

[67] H. Matter, J. Winter, and W. Triftshauser, J. Nucl. Mater. 88 273 (1980).

[68] G. Kogel, P. Sperr, W. Triftshauser, and S. J. Rothman, J. Nucl. Mater 131, 148 (1985).

[69] K. R. Lund, K. G. Lynn, M. H. Weber, C. Macchi, A. Somoza, A. Juan, and M. A. Okuniewski, J. Nucl. Mater. 466, 343 (2015).

[70] T. Sathiyasheela, A. Riyas, R. Sukanya, P. Mohanakrishnan, and S. C. Chetal, Nucl. Eng. Des. 265, 1149 (2013).

[71] C. Basak, G. J. Prasad, H. S. Kamath, and N. Prabhu, J. Alloys Compd. 480, 857 (2009).

[72] K. H. Timmesfeld and R. J. Elliott, Phys. Status Solidi 42, 859 (1970).

[73] C.-C. Fu, J. D. Torre, F. Willaime, J.-L. Bocquet, and A. Barbu, Nat. Mater. 4, 68 (2005).

[74] Y. Li, A. Chernatynskiy, J. R. Kennedy, S. B. Sinnott, and S. R. Phillpot, J. Nucl. Mater. 475, 6 (2016).

[75] M. J. Puska, S. Poykko, M. Pesola, and R. M. Nieminen, Phys. Rev. B 58, 1318 (1998).

[76] M. I. J. Probert and M. C. Payne, Phys. Rev. B 67, 075204 (2003).

[77] G. Lucas and R. Schaublin, Nucl. Instrum. Methods Phys. Res. B 267, 3009 (2009).

[78] N. P. Kobelev and V. A. Khonik, J. Exp. Theor. Phys. 126, 340 (2018).

[79] M. Posselt (private communication).

[80] K. Nordlund and R. Averback, in Handbook of Materials Modeling, edited by S. Yip (Springer, Berlin, 2005), pp. 18551876. 